\title{
Predicting lymph node metastasis for endoscopic resection of superficial esophageal squamous cell carcinoma
}

Dae Won Ma, MD, Da Hyun Jung, MD, Jie-Hyun Kim, MD, PhD, Jae Jun Park, MD, PhD, Young Hoon Youn, MD, PhD, and Hyojin Park, MD, PhD

\section{ABSTRACT}

Objective: The aims of this study were to identify risk factors for lymph node metastasis and develop a reliable risk stratification system.

Methods: Between May 2001 and December 2015, 262 patients who underwent endoscopic resection or surgery for superficial esophageal squamous cell carcinoma were enrolled. We evaluated possible predictive factors for lymph node metastasis: age, gender, tumor length, tumor area, circumferential spread, tumor location, gross appearance, depth of invasion, tumor differentiation, and lymphovascular invasion.

Results: The incidence of lymph node metastasis was $14.5 \%$ (38/262). In multivariate analysis, tumor size $(>15 \mathrm{~mm})$, depth of invasion (submucosal invasion), and lymphovascular invasion were significantly associated with lymph node metastasis. These factors were included in the risk stratification system and assigned scores; the total risk stratification system score was 0 to 6 . The area under the receiver operating characteristic curve for predicting lymph node metastasis was 0.869 (95\% confidence interval, 0.813-0.926). The high-risk group (risk stratification system score $\geq 3$ ) exhibited a significantly higher risk of lymph node metastasis than the low-risk group (score $<3)(26.5 \%$ vs $1.6 \%)$. There was no lymph node metastasis in patients with a risk stratification system of 0 . The sensitivity, specificity, positive predictive value, negative predictive value, and accuracy of the risk stratification system were $94.7 \%, 55.4 \%, 26.5 \%$, $98.4 \%$, and $61.1 \%$, respectively.

Conclusions: We developed a risk stratification system that should facilitate the identification of patients with a high or low risk of lymph node metastasis. This may aid the precise selection of patients who can undergo endoscopic resection. (J Thorac Cardiovasc Surg 2019;157:397-402)

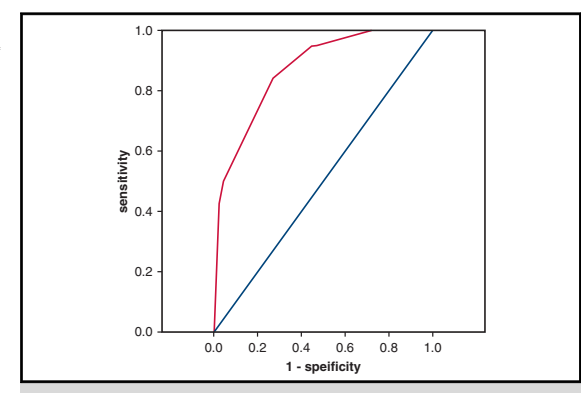

Receiver operating characteristic curves of the RSS

Central Message

Tumor size, LVI, and submucosal invasion were independent risk factors for LNM in patients with SESCC.

\section{Perspective}

We developed a simple RSS for the prediction of LNM, and it may be helpful in clinical practice by facilitating the precise selection of patients who can undergo ER. Also, we propose that if any of these risk factors do not apply to a tumor after ER, careful observation can be recommended.

See Editorial Commentary page 403
Esophageal cancer is the eighth most common malignancy in the world. ${ }^{1}$ In Korea, the detection rate of superficial esophageal squamous cell carcinoma (SESCC) during screening endoscopy has increased with the introduction of new endoscopic techniques, such as magnifying

\footnotetext{
From the Department of Internal Medicine, Gangnam Severance Hospital, Yonsei University College of Medicine, Seoul, Korea.

The Institutional Review Board of Gangnam Severance Hospital waived the need for approval of this study (29-8-2017, Institutional Review Board No. 3-2017-0185).

Received for publication Feb 12, 2018; revisions received July 5, 2018; accepted for publication July 6, 2018; available ahead of print Aug 22, 2018.

Address for reprints: Da Hyun Jung, MD, Department of Internal Medicine, Gangnam Severance Hospital, Yonsei University College of Medicine, 211 Eonjuro, Gangnam-gu, Seoul, Korea 135-720 (E-mail: leah1004@yuhs.ac). $0022-5223 / \$ 36.00$

Copyright (C) 2018 by The American Association for Thoracic Surgery https://doi.org/10.1016/j.jtcvs.2018.07.034
}

endoscopy and narrow-band imaging endoscopy. ${ }^{2}$ SESCC, defined as mucosal or submucosal esophageal cancer regardless of the presence or absence of lymph node metastasis (LNM), is associated with a better outcome because of its presentation at an early cancer stage. ${ }^{3,4}$ Surgical resection of the esophagus is considered the standard treatment for patients with SESCC. However, esophagectomy is associated with high morbidity and mortality rates. ${ }^{5-7}$ Furthermore, surgery

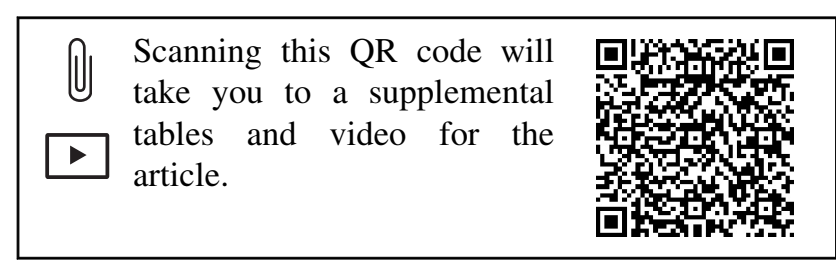




$$
\begin{aligned}
& \text { Abbreviations and Acronyms } \\
& \text { CI = confidence interval } \\
& \mathrm{ER} \quad=\text { endoscopic resection } \\
& \text { LNM = lymph node metastasis } \\
& \text { LVI = lymphovascular invasion } \\
& \mathrm{NPV}=\text { negative predictive value } \\
& \mathrm{OR}=\text { odds ratio } \\
& \text { ROC }=\text { receiver operating characteristic } \\
& \text { RSS = risk stratification system } \\
& \text { SESCC }=\text { superficial esophageal squamous cell } \\
& \text { carcinoma }
\end{aligned}
$$

cannot be performed in patients with an advanced age or multiple comorbidities.

Nowadays, endoscopic resection (ER) is widely used for the treatment of SESCC because it is minimally invasive and maintains the patient's quality of life. Several studies have reported that LNM of esophageal cancer can be detected by computed tomography, positron emission tomography, or endoscopic ultrasound. However, the accuracy of these methods is insufficient to completely exclude the presence of LNM. ${ }^{9-11}$ ER is a local treatment that does not include lymph node dissection. Thus, it is important to be able to predict LNM before ER because appropriate management of SESCC with LNM involves surgery or chemoradiotherapy.

Of the current indications for ER of SESCC, only the depth of tumor invasion is defined as a criterion. ${ }^{3}$ Yet, LNM is a key factor predicting the prognosis of SESCC. Therefore, we aimed to investigate the risk factors for LNM in SESCC and develop a reliable risk stratification system (RSS) for the prediction of LNM to establish the appropriate treatment strategy for SESCC.

\section{MATERIALS AND METHODS \\ Patients and Data Collection}

We retrospectively reviewed the medical records of all patients who underwent ER or esophagectomy for esophageal cancer at Severance and Gangnam Severance Hospital, Seoul, South Korea, from May 2001 to December 2015. We excluded those patients who received neoadjuvant chemotherapy or chemoradiotherapy as SESCC treatment. We excluded patients with insufficient data for a full pathologic analysis. However, patients who underwent ER and received additional surgery because of noncurative resection were included and analyzed according to the final pathology results. Thus, 262 patients were eligible for inclusion in our study. Patients enrolled in our study underwent endoscopic ultrasound, computed tomography, or positron emission tomography to determine the possibility of LNM. Endoscopic findings of the tumors were classified according to the Paris classification. ${ }^{12}$ Nonprotruding or nonexcavated type tumors were classified as flat type, and protruding or excavated type tumors were classified as nonflat type. The Institutional Review Board of Gangnam Severance Hospital waived the need for approval of this study (Institutional Review Board No. 3-2017-0185).

\section{Histopathologic Examination}

Surgical specimens were fixed in formaldehyde, and the tumor tissue and surrounding normal tissue were serially cut perpendicularly at 2- to 5-mm intervals. The size of tumor, tumor histology, depth of invasion, and presence of lymphovascular invasion (LVI) were evaluated according to the Japanese Classification of Esophageal Carcinoma. ${ }^{13}$ Mucosal cancer was divided into 3 subtypes according to the extent of invasion: $\mathrm{m} 1$, intraepithelial carcinoma; $\mathrm{m} 2$, cancer invading the lamina propria; and $\mathrm{m} 3$, cancer in contact with or invading the muscularis mucosa. Submucosal invasion was defined as a tumor extending beyond the muscularis mucosa. The location of tumor was classified according to the guidelines of the American Joint Committee on Cancer. ${ }^{14}$ The upper esophagus extended from the thoracic inlet to the level of the tracheal bifurcation, the mid-esophagus extended from the tracheal bifurcation to the distal esophagus just above the esophagogastric junction, and the lower esophagus contained the intra-abdominal portion of the esophagus and the esophagogastric junction.

\section{Statistical Analysis}

The chi-square test or Fisher exact test was used to compare categoric parameters. The Student $t$ test was used to compare continuous variables. The factors with 2 -sided $P$ values less than .05 in univariate analysis were included in a multivariate logistic regression analysis. Multivariate logistic regression analysis with backward stepwise selection was used to identify independent factors for predicting LNM. The Youden Index was used to identify the optimal cutoff value in the receiver operating characteristic (ROC) curve that maximized sensitivity and specificity. To define simple integer-based point scores for each predictive factor, the score of each valuable was weighted according to the beta coefficients obtained in the multivariate logistic regression model. To generate the scoring model, the beta coefficients were rounded to the nearest whole number. The total risk score for each patient was calculated by summing the scores of the individual risk factors. The Hosmer-Lemeshow test was used to confirm the goodness of fit. We obtained a calibration plot to confirm the agreement between the predicted probability and the actual probability based on the development model. The statistical calculations were performed using SPSS version 18.0 for Windows software (SPSS Inc, Chicago, Ill).

\section{RESULTS \\ Clinicopathologic Characteristics}

The clinicopathologic characteristics of the 262 patients (243 male; median age, 63.5 years; range, 35-83 years) are shown in Table 1. Among these patients, $81(30.9 \%)$ underwent ER and 181 (69.1\%) underwent esophageal surgery. According to the gross appearance, 106 patients $(40.5 \%)$ had a flat type tumor and 156 patients $(59.5 \%)$ had a nonflat type tumor. The median tumor size was $18 \mathrm{~mm}$ (range, 0.5-70 mm). According to the depth of tumor invasion, 129 patients $(49.2 \%)$ had mucosal cancer and 133 patients $(50.8 \%)$ had submucosal cancer. Regarding the tumor histology, 23 patients $(8.8 \%), 83$ patients $(31.7 \%), 137$ patients $(52.3 \%)$, and 19 patients $(7.3 \%)$ had carcinoma in situ, well-differentiated, moderately differentiated, and poorly differentiated tumors, respectively. LVI was found in 35 patients (13.4\%). LNM was diagnosed in 38 patients (14.5\%).

\section{Risk Factors for Lymph Node Metastasis in Superficial Esophageal Squamous Cell Carcinoma}

Table 2 shows comparisons of the clinicopathologic findings according to the presence or absence of LNM. 
TABLE 1. Patient clinicopathologic characteristics

\begin{tabular}{|c|c|}
\hline Characteristics & No. of patients $(n, \%)$ \\
\hline \multicolumn{2}{|l|}{ Gender } \\
\hline Male & $243(92.7)$ \\
\hline Female & $19(7.3)$ \\
\hline Age (y, median [range]) & $64(35-83)$ \\
\hline \multicolumn{2}{|l|}{ Pretreatment evaluation } \\
\hline Computed tomography & $262(100)$ \\
\hline Endoscopic ultrasound & $252(96.2)$ \\
\hline Positron emission tomography & $250(95.4)$ \\
\hline \multicolumn{2}{|l|}{ Treatment modality } \\
\hline ER & $81(30.9)$ \\
\hline Surgery & $181(69.1)$ \\
\hline Retrieved lymph node (median [range]) & $37(0-108)$ \\
\hline \multicolumn{2}{|l|}{ Tumor location within esophagus } \\
\hline Upper & $19(7.3)$ \\
\hline Middle & $77(29.4)$ \\
\hline Lower & $166(63.4)$ \\
\hline \multicolumn{2}{|l|}{ Tumor type on gross examination } \\
\hline Flat & $106(40.5)$ \\
\hline Nonflat & $156(59.5)$ \\
\hline Tumor size (mm, median [range]) & $18(0.5-70)$ \\
\hline \multicolumn{2}{|l|}{ Proportion of circumferential extension } \\
\hline$<1 / 4$ & $55(21.0)$ \\
\hline $1 / 4-2 / 4$ & $105(40.1)$ \\
\hline $2 / 4-3 / 4$ & $66(25.2)$ \\
\hline$\geq 3 / 4$ & $36(13.7)$ \\
\hline \multicolumn{2}{|l|}{ Depth of invasion } \\
\hline Epithelium & $23(8.8)$ \\
\hline Lamina propria & $59(22.5)$ \\
\hline Muscularis mucosa & $47(17.9)$ \\
\hline Submucosa & $133(50.8)$ \\
\hline \multicolumn{2}{|l|}{ Differentiation } \\
\hline Carcinoma in situ & $23(8.8)$ \\
\hline Well differentiated & $83(31.7)$ \\
\hline Moderately differentiated & $137(52.3)$ \\
\hline Poorly differentiated & $19(7.3)$ \\
\hline \multicolumn{2}{|l|}{ TNM stage* } \\
\hline Stage I & 254 (96.9) \\
\hline Stage II & $8(3.1)$ \\
\hline \multicolumn{2}{|l|}{ LVI } \\
\hline Absence & $227(86.6)$ \\
\hline Presence & $35(13.4)$ \\
\hline \multicolumn{2}{|l|}{ LNM } \\
\hline Absence & $224(85.5)$ \\
\hline Presence & $38(14.5)$ \\
\hline
\end{tabular}

ER, Endoscopic resection; TNM, tumor, node, metastasis; $L V I$, lymphovascular invasion; $L N M$, lymph node metastasis. *Quoted from American Joint Committee on Cancer 8th edition.

Tumor size (originally a continuous variable) was divided at $15 \mathrm{~mm}$, which was the value showing the highest area under the curve during ROC curve analysis. Univariate analysis showed that these variables were significantly associated with the presence of LNM: tumor size
$(P<.001)$, circumferential extension $(P=.005)$, gross appearance $(P=.004)$, depth of invasion $(P<.001)$, tumor differentiation $(P<.001)$, and LVI $(P<.001)$. On the contrary, age $(P=.069)$, gender $(P=.744)$, and tumor location $(P=.397)$ were not significantly associated with LNM. In multivariate logistic regression, tumor size (odds ratio $[\mathrm{OR}], 3.417 ; 95 \%$ confidence interval [CI], $1.280-9.122 ; P=.014)$, depth of invasion (OR, 15.757; 95\% CI, 3.577-69.402; $P<.001$ ), and LVI (OR, 8.699; 95\% CI, 3.494-21.657; $P<.001)$ were significantly associated with LNM (Table 3).

\section{Risk Stratification System for Prediction of Lymph Node Metastasis in Superficial Esophageal Squamous Cell Carcinoma}

We assigned a risk score to each predictor that showed a significant association with LNM in the multivariate analysis. Tumor size of more than $15 \mathrm{~mm}$ was assigned 1 point, submucosal invasion was assigned 3 points, and the presence of LVI was assigned 2 points (Table 4). We analyzed LNM by summing these 3 scores; the final total scores ranged from 0 to 6 . Because submucosal invasion was determined to be the most powerful risk factor of LNM, the patients were classified into 2 groups according to depth of invasion. In each group, the LNM rate was examined by subdividing the group according to LVI and tumor size. There was no LNM in patients with mucosal cancer and a tumor size less than $15 \mathrm{~mm}$. In patients with submucosal cancer, the LNM rate was almost double when the tumor size was at least $15 \mathrm{~mm}$, compared with less than $15 \mathrm{~mm}$, regardless of the presence or absence of LVI (LVI (-): $20.3 \%$ vs $10.0 \%$, LVI (+): $76.2 \%$ vs $37.5 \%$ ) (Table 5). LNM relative to tumor size and depth of invasion in SESCC was further analyzed (Table 6). If the depth of invasion was less than the muscularis mucosa, there was no LNM, irrespective of the tumor size. In contrast, if the tumor exhibited submucosal invasion, there was a possibility of LNM even if the tumor size was $15 \mathrm{~mm}$ or less $(14.6 \%)$.

The optimal cutoff value for LNM was 3 points on the RSS according to the ROC curve analysis (Table E1). Therefore, we divided the patients into 2 groups: a low-risk group (RSS score $<3$ points) and a high-risk group (RSS score $\geq 3$ points). We noted LNM in $1.6 \%(2 / 126)$ and $26.5 \%(36 / 136)$ of patients in the low- and high-risk groups, respectively. The sensitivity, specificity, positive predictive value, negative predictive value (NPV), and accuracy of the RSS were $94.7 \%$ (95\% CI, 0.81-0.99), 55.4\% (95\% CI, $0.49-0.62), 26.5 \%$ (95\% CI, 0.19-0.35), $98.4 \%(95 \% \mathrm{CI}$, $0.94-0.99$ ), and $61.1 \%$ (95\% CI, 0.56-0.65), respectively. The RSS showed good discrimination for detecting LNM (area under the curve $=0.869$ for the development data) (Figure 1). We confirmed the goodness of fit of the model with the Hosmer-Lemeshow test after establishing the 
TABLE 2. Clinicopathologic findings according to presence or absence of lymph node metastasis

\begin{tabular}{|c|c|c|c|}
\hline Variables & $\begin{array}{c}\mathbf{L N M}(-) \\
(\mathbf{n}=\mathbf{2 2 4}) \\
(\mathbf{n}, \%) \\
\end{array}$ & $\begin{array}{c}\mathbf{L N M}(+) \\
(\mathbf{n}=\mathbf{3 8}) \\
(\mathbf{n}, \%)\end{array}$ & $\boldsymbol{P}$ \\
\hline Age (y, median [range]) & $65.0(35-83)$ & $60.5(42-72)$ & .069 \\
\hline $\begin{array}{l}\text { Gender } \\
\text { Male } \\
\text { Female }\end{array}$ & $\begin{array}{c}208(92.9) \\
16(7.1)\end{array}$ & $\begin{array}{c}35(92.1) \\
3(7.9)\end{array}$ & .744 \\
\hline $\begin{array}{l}\text { Tumor size } \\
\quad \leq 15 \mathrm{~mm} \\
>15 \mathrm{~mm}\end{array}$ & $\begin{array}{l}105(46.9) \\
119(53.1)\end{array}$ & $\begin{array}{r}7(18.4) \\
31(81.6)\end{array}$ & .001 \\
\hline $\begin{array}{l}\text { Circumferential extension } \\
\quad<1 / 4 \\
1 / 4-2 / 4 \\
2 / 4-3 / 4 \\
\geq 3 / 4\end{array}$ & $\begin{array}{l}53(23.7) \\
89(39.7) \\
57(25.4) \\
25(11.2)\end{array}$ & $\begin{array}{r}2(5.3) \\
16(42.1) \\
9(23.7) \\
11(28.9)\end{array}$ & .005 \\
\hline $\begin{array}{l}\text { Location within esophagus } \\
\text { Upper third } \\
\text { Middle third } \\
\text { Lower third }\end{array}$ & $\begin{array}{r}15(6.7) \\
69(30.8) \\
140(62.5)\end{array}$ & $\begin{array}{r}4(10.5) \\
8(21.1) \\
26(68.4)\end{array}$ & .397 \\
\hline $\begin{array}{l}\text { Tumor type on gross examination } \\
\text { Flat } \\
\text { Nonflat }\end{array}$ & $\begin{array}{r}99(44.2) \\
125(55.8)\end{array}$ & $\begin{array}{r}7(18.4) \\
31(81.6)\end{array}$ & .004 \\
\hline $\begin{array}{l}\text { Depth of invasion } \\
\text { Mucosa } \\
\text { Submucosa }\end{array}$ & $\begin{array}{r}127(56.7) \\
97(43.3)\end{array}$ & $\begin{array}{c}2(5.3) \\
36(94.7)\end{array}$ & $<.001$ \\
\hline $\begin{array}{l}\text { Tumor differentiation } \\
\text { Carcinoma in situ } \\
\text { Well differentiated } \\
\text { Moderately differentiated } \\
\text { Poorly differentiated }\end{array}$ & $\begin{array}{r}23(10.3) \\
79(35.3) \\
108(48.2) \\
14(6.3)\end{array}$ & $\begin{aligned} & 0(0.0) \\
& 4(10.5) \\
& 29 \\
& 5(76.3) \\
& 5(13.2)\end{aligned}$ & $<.001$ \\
\hline $\begin{array}{l}\text { LVI } \\
\qquad \text { Absence } \\
\text { Presence }\end{array}$ & $\begin{array}{c}208(92.9) \\
16(7.1)\end{array}$ & $\begin{array}{l}19(50.0) \\
19(50.0)\end{array}$ & $<.001$ \\
\hline
\end{tabular}

LNM, Lymph node metastasis; $L V I$, lymphovascular invasion.

development model. The $P$ value was .7387. Therefore, the RSS model fitted well without overfitting. The predicted probability and the actual probability were almost identical to the 45-degree line in the calibration plot, indicating that

TABLE 3. Multivariate logistic regression analysis results for factors associated with lymph node metastasis

\begin{tabular}{lccr}
\hline \multicolumn{1}{c}{ Variables } & OR $(\mathbf{9 5} \% \mathbf{C I})$ & $\boldsymbol{P}$ value & Beta \\
\hline $\begin{array}{l}\text { Tumor size } \\
\leq 15 \mathrm{~mm}\end{array}$ & Reference & & \\
$>15 \mathrm{~mm}$ & $3.417(1.280-9.122)$ & .014 & 1.229 \\
$\begin{array}{l}\text { Depth of invasion } \\
\text { Mucosa }\end{array}$ & Reference & & \\
$\quad$ Submucosa & $15.757(3.577-69.402)$ & $<.001$ & 2.757 \\
LVI & & & \\
$\quad \begin{array}{l}\text { Absent } \\
\text { Present }\end{array}$ & Reference & & \\
\hline
\end{tabular}

$O R$, Odds ratio; $C I$, confidence interval; $L V I$, lymphovascular invasion.
TABLE 4. Risk stratification system for lymph node metastasis prediction

\begin{tabular}{lcccc}
\hline \multirow{2}{*}{ Factor } & \multicolumn{4}{c}{ Scores } \\
\cline { 2 - 5 } & $\mathbf{0}$ & $\mathbf{1}$ & $\mathbf{2}$ & $\mathbf{3}$ \\
\hline Tumor size $(\mathrm{mm})$ & $\leq 15$ & $>15$ & & \\
Depth of invasion & Mucosa & & & Submucosa \\
LVI & Absent & & Present & \\
\hline
\end{tabular}

LVI, Lymphovascular invasion.

the model fitted well (Figure 2). Also, we analyzed post hoc power to demonstrate the predictive power of the development model. The result was $96.91 \%$. Therefore, we regarded the development model was reliable.

\section{DISCUSSION}

Several previous studies revealed that the 5-year survivals of patients with esophageal cancer with mucosal and submucosal invasion were $83.5 \%$ to $87.6 \%$ and $54.9 \%$ to $63.6 \%$, respectively. ${ }^{15,16}$ Furthermore, the 5 -year survival of patients with submucosal invasion plus LNM was lower $(27.0 \%-43.6 \%){ }^{15,16}$ Therefore, LNM is one of the most important factors associated with a poor prognosis in SESCC, and the opportunity for cure can be reduced in cases of undetected LNM. ${ }^{17}$ According to guidelines of the Japanese Esophageal Society for the diagnosis and treatment of esophageal cancer, endoscopic treatment is principally indicated for patients with a low likelihood of LNM in whom the tumor is technically resectable by endoscopy. ${ }^{3}$ Therefore, it is crucial to know the risk of LNM for the management of SESCC. In the current study, we established an RSS to predict LNM in SESCC. The RSS showed good diagnostic accuracy for discrimination of high- and low-risk groups, and patients with a risk score of 0 had no LNM.

Our results showed that the independent predictive factors for LNM in patients with SESCC were tumor size, LVI, and depth of invasion. Circumferential extension, gross type, and tumor differentiation were significantly associated with LNM in univariate analysis, but they lost significance in multivariate analysis. Patients with a tumor size less than $15 \mathrm{~mm}$, no LVI, and mucosal cancer exhibited

TABLE 5. Lymph node metastasis rates according to tumor size, depth of invasion, and lymphovascular invasion

\begin{tabular}{|c|c|c|}
\hline Tumor size (mm) & $\operatorname{LVI}(-)(n, \%)$ & $\operatorname{LVI}(+)(\mathbf{n}, \%)$ \\
\hline \multicolumn{3}{|l|}{ Mucosal invasion $(\mathrm{n}=129)$} \\
\hline$\leq 15$ & $0 / 61(0.0)$ & $0 / 3(0.0)$ \\
\hline$>15$ & $2 / 62(3.2)$ & $0 / 3(0.0)$ \\
\hline \multicolumn{3}{|c|}{ Submucosal invasion $(\mathrm{n}=133)$} \\
\hline$\leq 15$ & $4 / 40(10.0)$ & $3 / 8(37.5)$ \\
\hline$>15$ & $13 / 64(20.3)$ & $16 / 21(76.2)$ \\
\hline
\end{tabular}

LVI, Lymphovascular invasion. 
TABLE 6. Lymph node metastasis rates according to tumor size and depth of invasion

\begin{tabular}{lcccc}
\hline Tumor size (mm) & M1 LNM (n, \%) & M2 LNM (n, \%) & M3 LNM (n, \%) & SM LNM (n, \%) \\
\hline$\leq 15$ & $0 / 12(0.0)$ & $0 / 31(0.0)$ & $0 / 23(0.0)$ & $7 / 48(14.6)$ \\
$>15, \leq 30$ & $0 / 8(0.0)$ & $0 / 17(0.0)$ & $1 / 17(5.9)$ & $18 / 58(31.0)$ \\
$>30$ & $0 / 3(0.0)$ & $0 / 11(0.0)$ & $1 / 7(14.3)$ & $11 / 27(40.7)$ \\
\hline
\end{tabular}

$M 1$, Epithelium; $L N M$, lymph node metastasis; $M 2$, lamina propria; $M 3$, muscularis mucosa; $S M$, submucosal.

no LNM (0/61). Our findings are in agreement with those of previous studies showing that LVI and depth of invasion were associated with LNM. ${ }^{18-22}$ We established an RSS using size, depth of invasion, and LVI to predict LNM in patients with SESCC. According to this RSS, we identified subgroups that should undergo surgery or systemic chemotherapy, not ER. In other studies, $1 \%$ to $11 \%$ of patients with mucosal invasion, in contrast to $16 \%$ to $49 \%$ of patients with submucosal invasion, exhibited LNM. ${ }^{23-25}$ There were only 2 patients with mucosal cancer who had LMN in our study $(1.6 \%$, $2 / 129)$, both of whom had muscularis mucosa invasion and a relatively large tumor $(>15 \mathrm{~mm})$. Although our model had a relatively low specificity (55.4\%) and positive predictive value $(26.5 \%)$, its sensitivity $(94.7 \%)$ and NPV (98.4\%) were high. Therefore, our RSS could be effective for detecting patients at high risk for LNM after noncurative ER (sensitivity, 94.7\%), and it should be particularly useful for excluding those at low risk for LNM (NPV, 98.4\%). Generally, the definitions for curative ER were en bloc resection, negative horizontal and vertical margins, and no LVI.

Li and colleagues ${ }^{18}$ reported a nonsignificant tendency toward an increased likelihood of LNM as tumor length

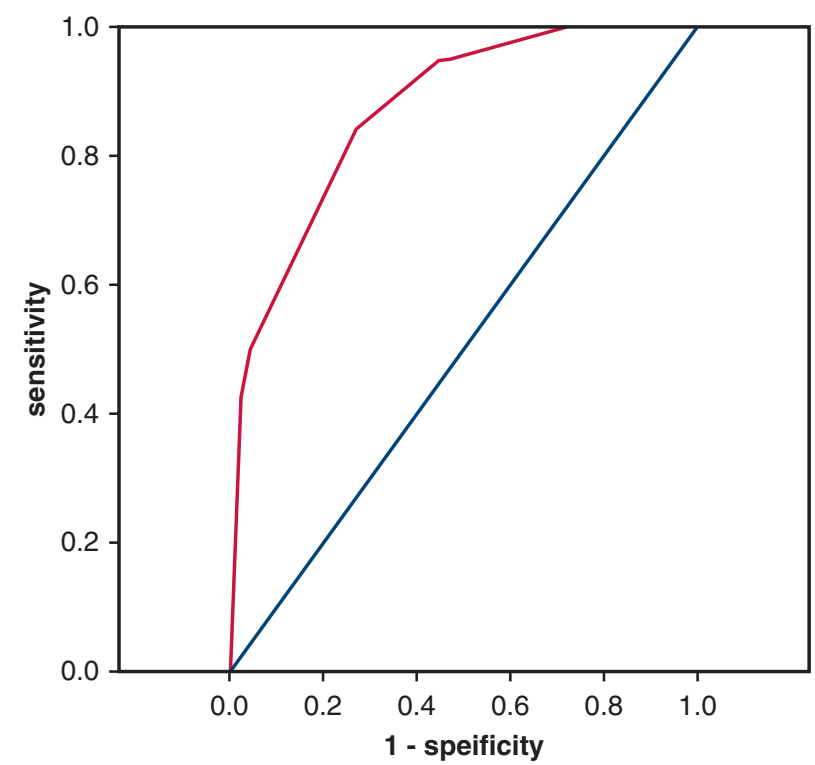

FIGURE 1. ROC curves of the RSS. Development data (area under the curve $=0.869,95 \%$ CI, 0.813-0.926). increased, but these findings were only confined to submucosal tumors. However, several studies showed opposite results. $^{8,22}$ Pech and colleagues ${ }^{26}$ reported that histologic differentiation was a potential risk factor for LNM. However, we found no significant association between tumor differentiation and LNM. According to the Japan Esophageal Society, the indication for ER of SESCC is a tumor confined within the epithelium or lamina propria mucosa. Lesions reaching the muscularis mucosa or slightly infiltrating the submucosa (up to $200 \mu \mathrm{m}$ ) are amenable to mucosal resection despite the risk of LNM, and these cases represent relative indications. ${ }^{3}$ Our data suggest that if a tumor has certain characteristics-size less than $15 \mathrm{~mm}$, no LVI, and confined to the mucosa-then the possibility of LNM is extremely low.

\section{Study Limitations}

There are some limitations in our study. First, it was a retrospective study, so it was not possible to completely eliminate some potential biases, such as selection, allocation, or measurement bias. Also, lack of external validation may be a limitation of our study. Therefore, further study will be needed to validate our RSS. Second, the sample size was relatively small, which restricted some of the analyses. For example, mucosa and submucosa

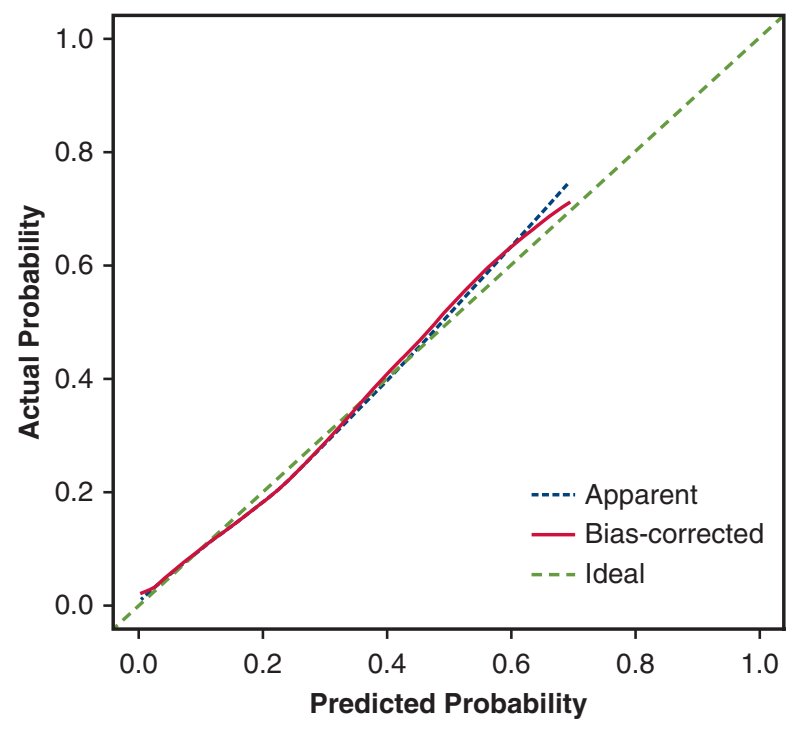

B $=200$ repetitions, boot $\quad$ Mean absolute error $=0.013 n=262$

FIGURE 2. Calibration plot for the development cohorts. 


\section{Predicting lymph node metastasis for endoscopic resection of superficial squamous cell carcinoma}

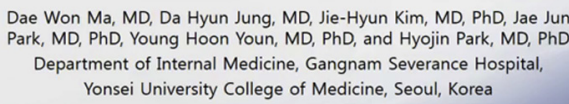

\section{(2) SEVERANC}

VIDEO 1. Importance and relevance of our study. Video available at: https://www.jtcvs.org/article/S0022-5223(18)32010-5/fulltext.

could not be classified into subgroups such as SM1, SM2, and SM3 during the analyses because of insufficient data. Furthermore, the incidence of LNM was low in the low-risk group. Therefore, the statistical power of low-risk group with high-risk features such as larger tumor size and LVI was inadequate. Third, it was impossible to dissect the lymph nodes in patients who had undergone ER. Although imaging studies, such as computed tomography, positron emission tomography, or endoscopic ultrasound, were performed before ER, the lack of histopathologic confirmation by surgical retrieval does not completely eliminate the possibility of LNM. However, when we reanalyzed data except cases of ER, the results were not changed (Tables E2 and E3).

\section{CONCLUSIONS}

We found that a tumor size of $15 \mathrm{~mm}$ or greater, LVI, and submucosal invasion were independent risk factors for LNM in patients with SESCC (Video 1). Furthermore, we developed a simple RSS for the prediction of LNM using these risk factors. This RSS may be helpful in clinical practice by facilitating the precise selection of patients who can undergo ER. On the basis of these data, we propose that if any of these risk factors do not apply to a tumor after ER, careful observation can be recommended.

\section{Conflict of Interest Statement}

Authors have nothing to disclose with regard to commercial support.

\section{References}

1. Jemal A, Siegel R, Ward E, Hao Y, Xu J, Murray T, et al. Cancer statistics, 2008 CA Cancer J Clin. 2008;58:71-96.

2. Kumagai Y, Monma K, Kawada K. Magnifying chromoendoscopy of the esophagus: in-vivo pathological diagnosis using an endocytoscopy system. Endoscopy. 2004;36:590-4.

3. Kuwano H, Nishimura Y, Oyama T, Kato H, Kitagawa Y, Kusano M, et al. Guidelines for diagnosis and treatment of carcinoma of the esophagus April 2012 edited by the Japan Esophageal Society. Esophagus. 2015;12:1-30.
4. Japanese Society for Esophageal D. Guidelines for the clinical and pathologic studies on carcinoma of the esophagus. Jpn J Surg. 1976;6:69-78.

5. Shimada H, Nabeya Y, Matsubara H, Okazumi S, Shiratori T, Shimizu T, et al. Prediction of lymph node status in patients with superficial esophageal carcinoma: analysis of 160 surgically resected cancers. Am J Surg. 2006;191: 250-4.

6. Roth JA, Putnam JB Jr. Surgery for cancer of the esophagus. Semin Oncol. 1994; 21:453-61.

7. Mitzman B, Lutfi W, Wang CH, Krantz S, Howington JA, Kim KW. Minimally invasive esophagectomy provides equivalent survival to open esophagectomy: an analysis of the National cancer database. Semin Thorac Cardiovasc Surg 2017;29:244-53.

8. Choi JY, Park YS, Jung HY, Ahn JY, Kim MY, Lee JH, et al. Feasibility of endoscopic resection in superficial esophageal squamous carcinoma. Gastrointest Endosc. 2011;73:881-9. 889.e1-2.

9. Kim K, Park SJ, Kim BT, Lee KS, Shim YM. Evaluation of lymph node metastases in squamous cell carcinoma of the esophagus with positron emission tomography. Ann Thorac Surg. 2001;71:290-4.

10. Lightdale CJ, Kulkarni KG. Role of endoscopic ultrasonography in the staging and follow-up of esophageal cancer. J Clin Oncol. 2005;23:4483-9.

11. Yoon YC, Lee KS, Shim YM, Kim BT, Kim K, Kim TS. Metastasis to regional lymph nodes in patients with esophageal squamous cell carcinoma: CT versus FDG PET for presurgical detection prospective study. Radiology. 2003;227: 764-70.

12. The Paris endoscopic classification of superficial neoplastic lesions: esophagus, stomach, and colon: November 30 to December 1, 2002. Gastrointest Endosc 2003;58:S3-43.

13. Shimoda T. Japanese classification of esophageal cancer, the 10th editionPathological part. Nihon Rinsho. 2011;69(Suppl 6):109-20.

14. Rice TW, Blackstone EH, Rusch VW. 7th edition of the AJCC cancer staging manual: esophagus and esophagogastric junction. Ann Surg Oncol. 2010;17: 1721-4.

15. Kato H, Tachimori Y, Watanabe H, Yamaguchi H, Ishikawa T, Itabashi M. Superficial esophageal carcinoma. Surgical treatment and the results. Cancer. 1990;66:2319-23.

16. Nabeya K, Nakata Y. Extent of resection and lymphadenectomy in early squamous cell esophageal cancer. Dis Esophagus. 1997;10:159-61.

17. Sabik JF, Rice TW, Goldblum JR, Koka A, Kirby TJ, Medendorp SV, et al. Superficial esophageal carcinoma. Ann Thorac Surg. 1995;60:896-902.

18. Li B, Chen H, Xiang J, Zhang Y, Kong Y, Garfield DH, et al. Prevalence of lymph node metastases in superficial esophageal squamous cell carcinoma. J Thorac Cardiovasc Surg. 2013;146:1198-203.

19. Moon JY, Kim GH, Kim JH, Kim HH, Ryu KD, Park SO, et al. Clinicopathologic factors predicting lymph node metastasis in superficial esophageal squamous cell carcinoma. Scand J Gastroenterol. 2014;49:589-94.

20. Pennathur A, Farkas A, Krasinskas AM, Ferson PF, Gooding WE, Gibson MK, et al. Esophagectomy for T1 esophageal cancer: outcomes in 100 patients and implications for endoscopic therapy. Ann Thorac Surg. 2009;87:1048-55.

21. Ancona E, Rampado S, Cassaro M, Battaglia G, Ruol A, Castoro C, et al. Prediction of lymph node status in superficial esophageal carcinoma. Ann Surg Oncol. 2008; 15:3278-88.

22. Kim DU, Lee JH, Min BH, Shim SG, Chang DK, Kim YH, et al. Risk factors of lymph node metastasis in T1 esophageal squamous cell carcinoma. J Gastroenterol Hepatol. 2008;23:619-25.

23. Wang GQ, Jiao GG, Chang FB, Fang WH, Song JX, Lu N, et al. Long-term results of operation for 420 patients with early squamous cell esophageal carcinoma discovered by screening. Ann Thorac Surg. 2004; 77:1740-4.

24. Endo M, Yoshino K, Kawano T, Nagai K, Inoue H. Clinicopathologic analysis of lymph node metastasis in surgically resected superficial cancer of the thoracic esophagus. Dis Esophagus. 2000;13:125-9.

25. Tajima Y, Nakanishi Y, Ochiai A, Tachimori Y, Kato H, Watanabe H, et al. Histopathologic findings predicting lymph node metastasis and prognosis of patients with superficial esophageal carcinoma: analysis of 240 surgically resected tumors. Cancer. 2000;88:1285-93.

26. Pech O, May A, Gossner L, Rabenstein T, Manner H, Huijsmans J, et al. Curative endoscopic therapy in patients with early esophageal squamous-cell carcinoma or high-grade intraepithelial neoplasia. Endoscopy. 2007;39:30-5.

Key Words: lymph node metastasis, risk stratification system, superficial esophageal squamous cell carcinoma 
TABLE E1. Identification of the optimal cutoff value in the receiver operating characteristic curve

\begin{tabular}{lcrr}
\hline Criterion & Predicted probability & Sensitivity $(\mathbf{9 5} \% \mathbf{C I})$ & Specificity $(\mathbf{9 5} \% \mathbf{C I})$ \\
\hline $0(\geq 0)$ & 0 & $100(90.7-100.0)$ & $0(0.0-1.6)$ \\
$1(>0)$ & 1.3 & $100(90.7-100.0)$ & $27.23(21.5-33.6)$ \\
$2(>1)$ & 3.6 & $94.74(82.3-99.4)$ & $54.02(47.3-60.7)$ \\
$3(>2)$ & 9.5 & $94.74(82.3-99.4)$ & $55.36(48.6-62.0)$ \\
$4(>3)$ & 22.6 & $84.21(68.7-94.0)$ & $72.77(66.4-78.5)$ \\
$5(>4)$ & 45.1 & $50(33.4-66.6)$ & $95.54(91.9-97.8)$ \\
$6(>5)$ & 69.7 & $42.11(26.3-59.2)$ & $97.77(94.9-99.3)$ \\
\hline
\end{tabular}

CI, Confidence interval.

TABLE E2. Clinicopathologic findings according to presence or absence of lymph node metastasis in surgical cases

\begin{tabular}{|c|c|c|c|}
\hline Variables & $\begin{array}{l}\operatorname{LNM}(-) \\
(\mathbf{n}=143) \\
(n, \%)\end{array}$ & $\begin{array}{c}\text { LNM (+) } \\
(\mathbf{n}=\mathbf{3 8}) \\
(\mathbf{n}, \%)\end{array}$ & $P$ \\
\hline Age (y, median [range]) & $65.0(45-83)$ & $60.5(42-72)$ & .259 \\
\hline $\begin{array}{l}\text { Gender } \\
\text { Male } \\
\text { Female }\end{array}$ & $\begin{array}{c}132(92.3) \\
11(7.7)\end{array}$ & $\begin{array}{c}35(92.1) \\
3(7.9)\end{array}$ & .967 \\
\hline $\begin{array}{l}\text { Tumor size } \\
\qquad 15 \mathrm{~mm} \\
>15 \mathrm{~mm}\end{array}$ & $\begin{array}{l}66(46.2) \\
77(53.8)\end{array}$ & $\begin{array}{r}7(18.4) \\
31(81.6)\end{array}$ & .001 \\
\hline $\begin{array}{l}\text { Circumferential extension } \\
\quad<1 / 4 \\
1 / 4-2 / 4 \\
2 / 4-3 / 4 \\
\geq 3 / 4\end{array}$ & $\begin{array}{l}17(11.9) \\
55(38.5) \\
46(32.2) \\
25(17.5)\end{array}$ & $\begin{aligned} 2 & (5.3) \\
16 & (42.1) \\
9 & (23.7) \\
11 & (28.9)\end{aligned}$ & .256 \\
\hline $\begin{array}{l}\text { Location within esophagus } \\
\text { Upper third } \\
\text { Middle third } \\
\text { Lower third }\end{array}$ & $\begin{array}{c}5(3.5) \\
44(30.8) \\
94(65.7)\end{array}$ & $\begin{array}{r}4(10.5) \\
8(21.1) \\
26(68.4)\end{array}$ & .135 \\
\hline $\begin{array}{l}\text { Tumor type on gross examination } \\
\text { Flat } \\
\text { Nonflat }\end{array}$ & $\begin{array}{l}53(37.1) \\
90(62.9)\end{array}$ & $\begin{array}{r}7(18.4) \\
31(81.6)\end{array}$ & .021 \\
\hline $\begin{array}{l}\text { Depth of invasion } \\
\text { Mucosa } \\
\text { Submucosa }\end{array}$ & $\begin{array}{l}64(44.8) \\
79(55.2)\end{array}$ & $\begin{array}{c}2(5.3) \\
36(94.7)\end{array}$ & $<.001$ \\
\hline $\begin{array}{l}\text { Tumor differentiation } \\
\text { Carcinoma in situ } \\
\text { Well differentiated } \\
\text { Moderately differentiated } \\
\text { Poorly differentiated }\end{array}$ & $\begin{array}{c}9(6.3) \\
38(26.6) \\
85(59.4) \\
11(7.7)\end{array}$ & $\begin{aligned} 0 & (0.0) \\
4 & (10.5) \\
29 & (76.3) \\
5 & (13.2)\end{aligned}$ & .044 \\
\hline $\begin{array}{l}\text { LVI } \\
\text { Absence } \\
\text { Presence }\end{array}$ & $\begin{array}{c}132(92.3) \\
11(7.7)\end{array}$ & $\begin{array}{l}19(50.0) \\
19(50.0)\end{array}$ & $<.001$ \\
\hline
\end{tabular}

$L N M$, Lymph node metastasis; $L V I$, lymphovascular invasion.
TABLE E3. Multivariate logistic regression analysis results for factors associated with lymph node metastasis in surgical cases

\begin{tabular}{|c|c|c|c|}
\hline Variables & OR $(95 \%$ CI $)$ & $P$ value & Beta \\
\hline \multicolumn{4}{|l|}{ Tumor size } \\
\hline$\leq 15 \mathrm{~mm}$ & Reference & & \\
\hline$>15 \mathrm{~mm}$ & $2.838(1.069-7.535)$ & .036 & 1.043 \\
\hline \multicolumn{4}{|c|}{ Depth of invasion } \\
\hline Mucosa & Reference & & \\
\hline Submucosa & $9.941(2.221-44.503)$ & .003 & 2.297 \\
\hline \multicolumn{4}{|l|}{ LVI } \\
\hline Absent & Reference & & \\
\hline Present & $7.252(2.777-18.938)$ & $<.001$ & 1.981 \\
\hline
\end{tabular}

